\title{
99mTc-MIBI imaging in thyroid nodules: Is it useful?
}

\author{
Raffaele Giubbini · Francesco Bertagna
}

Received: 6 August 2013/Accepted: 28 August 2013/Published online: 28 February 2014

(C) Springer Science+Business Media New York 2014

Treglia et al. [1] have recently proposed a meta-analysis evaluating the diagnostic performance of $99 \mathrm{mTc}-\mathrm{MIBI}$ scan in predicting the malignancy of thyroid nodules.

$99 \mathrm{~m}-\mathrm{Tc}$ is registered and adopted worldwide for myocardial perfusion imaging and for the diagnostic work-up of hyperparathyroidism. Furthermore there are reports on the use of $99 \mathrm{mTc}-\mathrm{MIBI}$ imaging in post-surgical evaluation of thyroid cancer, for residual tumor localization, especially when the 131I-Na whole-body scan is negative with detectable values of thyroglobulin [2]. However, this indication has been almost completely replaced by $18 \mathrm{~F}-$ FDG PET/CT imaging [3].

Treglia and colleagues reported the results of 21 studies, accurately selected by rigorous methodology out of 690 articles. The 21 pooled studies included nearly two thousand patients. They have demonstrated that the $99 \mathrm{mTc}-$ MIBI scintigraphy has good sensitivity, although suboptimal specificity, in predicting histological malignancy of thyroid nodules. These results offer a solid background for considering the clinical usefulness of 99mTc-MIBI imaging in a clinical setting.

No indications to perform a 99mTc-MIBI scintigraphy are reported in guidelines or algorithms of diagnostic workup of thyroid nodules [4], that is mainly based on the wide use of ultrasounds and cytology after echo-guided fineneedle aspiration (FNA).

The question that the paper of Treglia rises is related to the additional value, if any, of molecular imaging by 99mTc-MIBI over the traditional, standardized patient work-up.

R. Giubbini $(\bowtie) \cdot$ F. Bertagna

Department of Nuclear Medicine, University of Brescia, Brescia, Italy

e-mail: giubbini@med.unibs.it
FNA is frequently inconclusive when Class 3 follicularpatterned lesions are detected, including follicular neoplasms, Hürthle cell lesions, and the follicular variant of PTC. In centers with specific experience in thyroid cytology, follicular cytologic findings may be further subdivided into "follicular lesion/atypia of undetermined significance" and "follicular neoplasm." This distinction separates two cytologic groups at different risks for thyroid malignancy but with the same operative indications [4]. Preliminary data seem to demonstrate that (99m)Tc-MIBI scintigraphy is an adjunctive method to predict preoperatively the malignant behavior of nononcocytic follicular thyroid nodules indeterminate at FNA biopsy [5], whereas it does not show same accuracy in Hürthle cell tumors [6, 7]. Further, multicenter studies are required to accept this hypothesis. This is a crucial point in the diagnosis of thyroid nodules as other techniques fail to offer meaningful results. In a recent study aimed to determine the rate of malignancy and the ultrasonographic features that could be used as predictor of malignant pathologies at the nodules with indeterminate cytology, Tutuncu et al. [8] have seen that ultrasound is not accurate enough to exclude malignancy in this high-risk population. Our group has recently analyzed the clinical significance of thyroid focal uptake of 18F-FDG in patients who underwent PET/CT for nonthyroid diseases [9]. Two hundred and eleven patients $(28.9 \%)$ underwent further investigation to determine the nature of the nodule; $124 / 211$ (58.8\%) incidentalomas were benign, 72/211 (34.1\%) were malignant, 4/211 $(1.9 \%)$ were non-diagnostic at cytological examination in the absence of surgery and histological evaluation, and $11 / 211(5.2 \%)$ were indeterminate at cytological examination. Thus 18F-FDG focal uptake in thyroid nodules by PET does not seem to be able to discriminate between benign and malignant tissues. The thin core biopsy seems 
to be more promising, that should help to discern the nature of thyroid lesions cytologically classified as indeterminate, and it could be used as a complementary test in thyroid nodule assessment [10]. There are, however, critical points in applying this technique: it is invasive, it requires a specific technical skill, and the experience is still limited to few centers which have recruited a limited number of patients. A confirmation in multicenter studies and in larger populations is, therefore, mandatory. Another question that needs to be addressed is the smaller thyroid nodule size that can be detected by planar scintigraphy and SPECT. Does this technique have any clinical value for nodules in the range between 0.5 and $1.5 \mathrm{~cm}$ ?

Finally, is the intensity of sestamibi uptake a marker of cancer malignancy able to identify high-risk patients who may require more aggressive therapy after surgery?

Finding an answer to these questions is not easy as it would require perspectives studies recruiting a sufficient number of patients, but the paper of Treglia et al. [1] fixes the values of sensitivity and specificity of 99mTc-MIBI imaging and it may represent a starting point opening the route to new perspectives, able to identify the clinical usefulness of $99 \mathrm{mTc}-\mathrm{MIBI}$ in the preoperative evaluation of thyroid nodules.

\section{References}

1. G. Treglia, C. Caldarella, E. Saggiorato, L. Ceriani, F. Orlandi, M. Salvatori, L. Giovanella, Diagnostic performance of $99 \mathrm{mTc}-$ MIBI scan in predicting the malignancy of thyroid nodules: a meta-analysis. Endocrine 44(1), 70-78 (2013)

2. S. Dadparvar, A. Chevres, M. Tulchinsky, L. Krishna-Badrinath, A.S. Khan, W.J. Slizofski, Clinical utility of technetium-99m methoxisobutylisonitrile imaging in differentiated thyroid carcinoma: comparison with thallium-201 and iodine-131 Na scintigraphy, and serum thyroglobulin quantitation. Eur. J. Nucl. Med. 22, 1330-1338 (1995)

3. F. Bertagna, G. Bosio, G. Biasiotto, C. Rodella, E. Puta, S. Gabanelli, S. Lucchini, G. Merli, G. Savelli, R. Giubbini, J. Rosenbaum, A. Alavi, F-18 FDG-PET/CT evaluation of patients with differentiated thyroid cancer with negative I-131 total body scan and high thyroglobulin level. Clin. Nucl. Med. 34, 756-761 (2009)

4. AACE/AME/ETA Thyroid Nodule Guidelines, Endocr Pract. 16(Suppl 1) 7 (2010)

5. E. Saggiorato, T. Angusti, R. Rosas, M. Martinese, M. Finessi, F. Arecco, E. Trevisiol, N. Bergero, B. Puligheddu, M. Volante, V. Podio, M. Papotti, F. Orlandi, 99mTc-MIBI Imaging in the presurgical characterization of thyroid follicular neoplasms: relationship to multidrug resistance protein expression. J. Nucl. Med. 50, 1785-1793 (2009)

6. F. Boi, M.L. Lai, C. Deias, M. Piga, A. Serra, A. Uccheddu, G. Faa, S. Mariotti, The usefulness of $99 \mathrm{mTc}-$ SestaMIBI scan in the diagnostic evaluation of thyroid nodules with oncocytic cytology. Eur. J. Endocrinol. 149, 493-498 (2003)

7. A. Pisanu, L. Sias, A. Uccheddu, Factors predicting malignancy of Hürthle cell tumors of the thyroid: influence on surgical treatment. World J. Surg. 28, 761-765 (2004)

8. Tutuncu, Y., Berker, D., Isik, S., Akbaba, G., Ozuguz, U., Kucukler, F.K., Göcmen, E., Yalcın, Y., Aydin, Y., Guler, S. (2013) The frequency of malignancy and the relationship between malignancy and ultrasonographic features of thyroid nodules with indeterminate cytology. Endocrine doi:10.1016/S09536205(13)00078-2-j

9. F. Bertagna, G. Treglia, A. Piccardo, E. Giovannini, G. Bosio, G. Biasiotto, K. el Bahij, R. Maroldi, R. Giubbini, F18-FDG-PET/ CT thyroid incidentalomas: a wide retrospective analysis in three Italian centres on the significance of focal uptake and SUV value. Endocrine 43, 678-685 (2013)

10. N. Nasrollah, P. Trimboli, L. Guidobaldi, C. Ventura, G. Ramacciato, S. Taccogna, F. Romanelli, S. Valabrega, A. Crescenzi, Thin core biopsyshould help to discriminate thyroid nodules cytologically classified asindeterminate. A new sampling technique. Endocrine 43, 659-665 (2013) 